\title{
On the fragility of $\mathrm{Cu}_{47} \mathrm{Ti}_{33} \mathrm{Zr}_{11} \mathrm{Ni}_{8} \mathrm{Si}_{1}$ metallic glass
}

\author{
S Venkataraman ${ }^{1,5}$, K Biswas ${ }^{2}$, B C Wei ${ }^{3}$, D J Sordelet $^{4}$ and \\ J Eckert ${ }^{1}$ \\ ${ }^{1}$ FG Physikalische Metallkunde, FB 11, Material- und Geowissenschaften, Technische \\ Universität Darmstadt, Petersenstraße 23, D-64287 Darmstadt, Germany \\ ${ }^{2}$ Leibniz-Institut für Festkörper- und Werkstoffforschung Dresden, Helmholtzstraße 20, \\ D-01069 Dresden, Germany \\ ${ }^{3}$ National Microgravity Laboratory, Institute of Mechanics, Chinese Academy of Sciences, \\ 100080 Beijing, People's Republic of China \\ ${ }^{4}$ Materials and Engineering Physics Program, Ames Laboratory (USDOE), \\ Iowa State University, Ames, Iowa, IA 50014, USA \\ E-mail: s.venkataraman@phm.tu-darmstadt.de
}

Received 2 March 2006, in final form 3 March 2006

Published 2 June 2006

Online at stacks.iop.org/JPhysD/39/2600

\begin{abstract}
This study reports on calorimetric measurements of the glass transition at various heating rates stretching over three orders of magnitude for $\mathrm{Cu}_{47} \mathrm{Ti}_{33} \mathrm{Zr}_{11} \mathrm{Ni}_{8} \mathrm{Si}_{1}$ metallic glass powders synthesized by gas-atomization and subjected to varying thermal treatments. A Vogel-Fulcher-Tammann-type relation was fitted to the data recorded for the heating rate dependent shift of the glass transition. The fragility of the alloy is evaluated in terms of the fragility parameter. Its value is 44 for the as-prepared $\mathrm{Cu}_{47} \mathrm{Ti}_{33} \mathrm{Zr}_{11} \mathrm{Ni}_{8} \mathrm{Si}_{1}$ metallic glass powder and decreases with increasing annealing treatment temperature. The decrease in the fragility parameter is due to partial crystallization, which shifts the composition of the remaining supercooled liquid to that of a strong glass-forming alloy.
\end{abstract}

\section{Introduction}

The discovery of improved physical and mechanical properties of multicomponent metallic glasses has led to increased research in this area [1-5]. The possibility of preparing metallic glasses at cooling rates as low as $1-100 \mathrm{~K} \mathrm{~s}^{-1}$ has generated a lot of attention because this enables these alloys to be manufactured not only in the form of ribbons, but also in the form of bulk materials, known as bulk metallic glasses (BMGs) [2-5]. To further develop this possibility, a greater understanding of the glass-forming ability (GFA) of these systems is essential. GFA can be defined as the ease with which the melt of a metallic material can vitrify and is conventionally evaluated in terms of the critical cooling rate $\left(R_{\mathrm{c}}\right)$, defined as the minimum cooling rate necessary for freezing the melt into a glass without any precipitation of crystals during solidification [6]. The smaller the $R_{\mathrm{c}}$, the higher the GFA of a system should be. However, $R_{\mathrm{c}}$ is a parameter that is difficult to measure precisely. As a result, numerous criteria have been

5 Author to whom any correspondence should be addressed. proposed to reflect the GFA of different BMGs on the basis of characteristic temperatures measured by differential scanning calorimetry (DSC) and/or differential thermal analysis [7]. The most widely used criteria are the reduced glass transition criterion proposed by Spaepen and Turnbull [8], $T_{\mathrm{rg}}$, defined as the ratio of the glass transition temperature $\left(T_{\mathrm{g}}\right)$ and the liquidus temperature $\left(T_{1}\right)$, as well as the concept of using the width of the supercooled liquid region, $\Delta T$, defined as the temperature difference between the onset glass transition temperature, $T_{\mathrm{g}}$, and the onset crystallization temperature, $T_{\mathrm{x}}$ [4]. It has been proposed that the larger the $\Delta T$ and/or $T_{\mathrm{rg}}$, the lower is the critical cooling rate and hence higher the GFA [4]. However, this is not always true, since there are many notable exceptions to this rule. For example, in the case of $\mathrm{Zr}-\mathrm{Ti}-\mathrm{Cu}-\mathrm{Ni}-\mathrm{Be}$ alloys it has been found that the compositions with the largest $\Delta T$ are the poorest glass formers in the system [9]. On the other hand, it was found that the $T_{\mathrm{rg}}$ ratio relates well with the GFA in the $\mathrm{Zr}-\mathrm{Ti}-\mathrm{Cu}-\mathrm{Ni}-\mathrm{Be}$ system [9]. In contrast, the GFA in the case of Pd-Ni-Fe-P [10], Fe-(Co,Cr,Mo,Ga,Sb)-P-B-C [11] as well as $\mathrm{Mg}_{65} \mathrm{Cu}_{15} \mathrm{Y}_{10} \mathrm{M}_{10}(\mathrm{M}=\mathrm{Ni}, \mathrm{Al}, \mathrm{Zn}, \mathrm{Mn})$ [12] alloy 
systems is better explained on the basis of the $\Delta T$ values rather than the $T_{\mathrm{rg}}$ values. Although the $\Delta T$ as well as $T_{\mathrm{rg}}$ are the most widely used parameters there have been numerous other parameters developed over the years, which have been used to reflect the GFA in metallic alloys [7,13-18]. However, to date, there exists no single unified criterion, which can explain the GFA effectively.

One of the pioneering works for evaluating the GFA of supercooled liquids is the concept of fragility, as introduced by Angell $[19,20]$. According to this concept, glass-forming liquids can be classified into three general categories, i.e. strong glass formers, which show an Arrhenius behaviour in the Angell plot, fragile glass formers in which the temperature dependence of the viscosity is of non-Arrehnius type but can be fitted by a Vogel-Fulcher-Tammann (VFT) type relation, as described later in the section 3 , and intermediate glass formers, which lie between the strong and the fragile glass formers [20]. The fragility (Angell) plots are conventionally evaluated on the basis of viscosity data [20]. However, it has been shown that the heating rate dependence of $T_{\mathrm{g}}$ as measured in a DSC cell can also adequately be used to describe the fragility [21,22]. There have been numerous reports where the GFA of metallic glasses has been analyzed in terms of the fragility concept using calorimetric data. These reports deal with Mg-base [22,23], Fe-base [24, 25], Co-base [26], Pr-base [27], Ti-base [28], Zr-base [29] and Nb-Ni [29] metallic glasses. But so far there have been only a few investigations on the fragility of $\mathrm{Cu}$-base metallic glasses [30,31].

$\mathrm{Cu}$-base BMGs have been found in $\mathrm{Cu}-\mathrm{Ti}-\mathrm{Zr}-\mathrm{Ni}$ [32], $\mathrm{Cu}-\mathrm{Ti}-\mathrm{Zr}-\mathrm{Si}-\mathrm{B}$ [33], $\mathrm{Cu}-\mathrm{Ti}-\mathrm{Zr}-\mathrm{Ni}-\mathrm{Sn}$ [34], $\mathrm{Cu}-\mathrm{Zr} / \mathrm{Hf}-\mathrm{Ti}$ [35], $\mathrm{Cu}-\mathrm{Ti}-\mathrm{Zr}-\mathrm{Nb}-\mathrm{Ni}-\mathrm{Si}$ [36], $\mathrm{Cu}-\mathrm{Zr}-\mathrm{Al}$ [37], $\mathrm{Cu}-\mathrm{Zr}$ [38-40], $\mathrm{Cu}-\mathrm{Zr}-\mathrm{Ag}$ [41] as well as in the $\mathrm{Cu}-\mathrm{Ni}-\mathrm{Ag}-\mathrm{Zr}-\mathrm{Ti}$ [18] system recently and have attracted much interest because of their good GFA as well as mechanical properties. Of particular interest is the $\mathrm{Cu}_{47} \mathrm{Ti}_{33} \mathrm{Zr}_{11} \mathrm{Ni}_{8} \mathrm{Si}_{1}$ alloy. This alloy composition has an excellent GFA as manifested by an extended supercooled liquid region of $62 \mathrm{~K}$ and an estimated $R_{\mathrm{c}}$ on the order of $70 \mathrm{~K} \mathrm{~s}^{-1}[42,43]$. The addition of 1 at. $\% \mathrm{Si}$ to the $\mathrm{Cu}_{47} \mathrm{Ti}_{34} \mathrm{Zr}_{11} \mathrm{Ni}_{8}$ base alloy is beneficial in increasing the GFA [42]. The very fact that there are numerous reports on the formation of $\mathrm{Cu}_{47} \mathrm{Ti}_{33} \mathrm{Zr}_{11} \mathrm{Ni}_{8} \mathrm{Si}_{1}$ glass, albeit with contrasting results [42-44], suggests that it is a rather well-studied system. However, there are no reports on the fragility of this metallic glass. A previous study on the fragility of the very similar $\mathrm{Cu}_{47} \mathrm{Ti}_{34} \mathrm{Zr}_{11} \mathrm{Ni}_{8}$ BMG based on viscosity data showed that the fragility parameter is $59[30,45]$. On the other hand, Tang et al reported a fragility parameter of 62 for the binary $\mathrm{Cu}_{50} \mathrm{Zr}_{50}$ BMG based on DSC measurements [31]. It has been shown that the fragility parameter is a good indicator of the GFA of glass-forming liquids and the smaller the fragility parameter the lower is the $R_{\mathrm{c}}$ [30].

In this paper, the fragility of the $\mathrm{Cu}_{47} \mathrm{Ti}_{33} \mathrm{Zr}_{11} \mathrm{Ni}_{8} \mathrm{Si}_{1}$ glassy powders synthesized by gas atomization has been studied using DSC. After determining $T_{\mathrm{g}}$ from isochronal DSC scans, the data were fitted with a VFT-type relation and the fragility parameter was calculated. Additionally, the influence of isothermal treatment on the fragility of the glass/supercooled liquid is also studied and compared with that in the as-prepared state.

\section{Experimental methods}

$\mathrm{Cu}_{47} \mathrm{Ti}_{33} \mathrm{Zr}_{11} \mathrm{Ni}_{8} \mathrm{Si}_{1}$ powders were produced by high pressure Ar gas atomization at a dynamic pressure of $2.8 \mathrm{MPa}$ after heating a pre-alloy to $1623 \mathrm{~K}$ using a close coupled annular nozzle having a melt delivery inner diameter of $3.2 \mathrm{~mm}$ at Ames Laboratory [46]. The purity of the starting elements used to prepare the prealloy ranged from $99.9 \%$ to $99.999 \%$. The size of the powder particles used in the present study is $45-53 \mu \mathrm{m}$. To investigate the effect of isothermal annealing, the as-atomized metallic glass powder (referred to as alloy A) was annealed at $688 \mathrm{~K}$ for $60 \mathrm{~min}$ (referred to as alloy B) and at $723 \mathrm{~K}$ for $30 \mathrm{~min}$ (referred to as alloy $\mathrm{C}$ ). The isothermal annealing of the powder samples was done in a vacuum furnace operated at $1 \cdot 10^{-3}$ bar. Structural characterization was carried out by x-ray diffraction (XRD) measurements. The XRD patterns were recorded at room temperature using a Philips X-ray diffractometer with Co $\mathrm{K}_{\alpha}$ radiation $(\lambda=0.179 \mathrm{~nm})$. Thermal analysis of the powders was done with a Perkin-Elmer Diamond DSC differential scanning calorimeter (DSC) under flowing argon atmosphere at constant heating rates ranging from 0.08 to $3.33 \mathrm{~K} \mathrm{~s}^{-1}$. The calorimeter was calibrated for each heating rate using the melting transition of indium and zinc standards in order to account for the temperature shift on changing heating rates. A second run on each specimen was directly carried out after the first cycle without changing the conditions of the measurement to construct a baseline. Additionally, in case of alloy A, the powders were initially heated to $703 \mathrm{~K}$ at $0.66 \mathrm{~K} \mathrm{~s}^{-1}$ and cooled at $1.66 \mathrm{~K} \mathrm{~s}^{-1}$ in order to achieve a relaxed state prior to thermal analysis. The onset values of the glass transition, $T_{\mathrm{g}}$, as well as the onset value of first crystallization event, $T_{\mathrm{x}}$, were determined directly from the DSC curves. $T_{\mathrm{g}}$ was defined as the point of intersection between the linearly extrapolated curve below the transition with the steepest tangent of the rise in the heat flow signal [21]. Microstructural characterization of the atomized powders was accomplished by transmission electron microscopy (TEM) investigations, which were performed on ion-milled powder samples using a JEOL 2000 FX TEM operated at $200 \mathrm{kV}$.

\section{Results}

\subsection{Structural and microstructural characterization}

Figure 1 shows the XRD patterns of the $\mathrm{Cu}_{47} \mathrm{Ti}_{33} \mathrm{Zr}_{11} \mathrm{Ni}_{8} \mathrm{Si}_{1}$ powder in the as-atomized condition as well as after different annealing treatments. The pattern for the as-prepared powder (alloy A) only consists of broad diffraction maxima, which are characteristic for an amorphous phase. The XRD pattern for the powders annealed for $60 \mathrm{~min}$ at $688 \mathrm{~K}$ (alloy B) as well as that for the alloy annealed at $723 \mathrm{~K}$ for $30 \mathrm{~min}$ (alloy C) also exhibit no visible crystalline reflections within the sensitivity limits of XRD. The scattering vector, defined as $Q_{p}=$ $4 \pi \sin \theta_{\max } / \lambda\left(\theta_{\max }\right.$ corresponding to the diffraction angle of the first amorphous maximum and $\lambda$ being the wavelength of the $\mathrm{Co}_{\alpha}$ radiation), calculated by fitting the first broad peak at $2 \theta \approx 45^{\circ}$ (shown in figure 1) using Gauss line profiles, is $29 \pm 0.02 \mathrm{~nm}^{-1}$ in all cases. Although the $Q_{p}$ value suggests a very similar short-range order for all the alloys there is a reduction in the peak width at half maximum (FWHM). The 
FWHM decreases by a factor of $15 \%$ from the as-prepared state (alloy A) to the sample annealed at $723 \mathrm{~K}$ for $30 \mathrm{~min}$ (alloy C).

In order to study the possible microstructural alterations caused by annealing, TEM characterization was done for all the powders. Figure 2( $a$ ) shows a characteristic bright field TEM image and the corresponding selected area diffraction (SAD) pattern for alloy A. The bright field image shows no contrast resembling crystalline structures and the SAD pattern shows diffuse halo rings, i.e. characteristic features of an amorphous structure. In the case of alloy B (figure 2(b)), the bright field image exhibits an uneven contrast and the first diffuse amorphous halo becomes much narrower as compared with the diffraction pattern of alloy A (figure $2(a)$ ). The second ring is more pronounced and a third very faint ring appears.

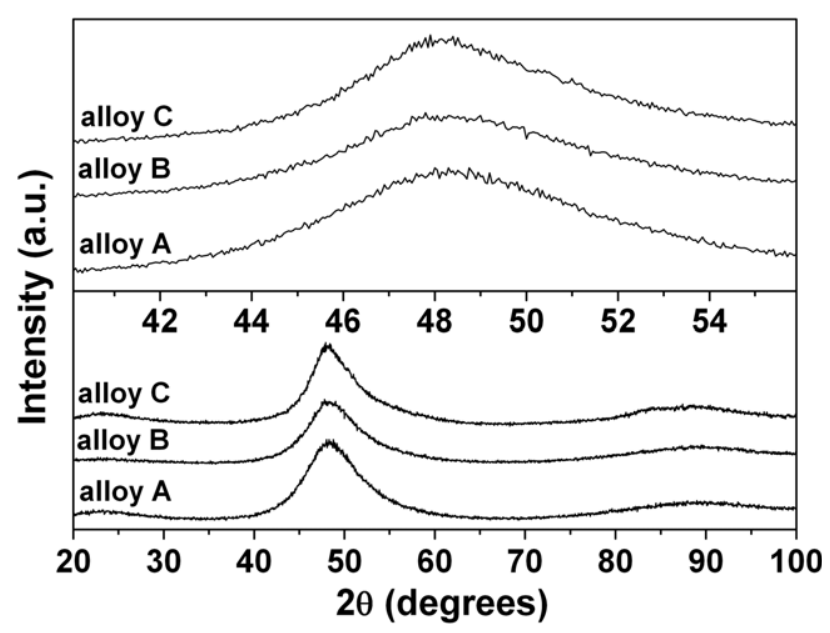

Figure 1. XRD patterns of $\mathrm{Cu}_{47} \mathrm{Ti}_{33} \mathrm{Zr}_{11} \mathrm{Ni}_{8} \mathrm{Si}_{1}$ powders in the as-prepared state (alloy A), after isothermal treatment at $688 \mathrm{~K}$ for $60 \mathrm{~min}$ (alloy B) and after isothermal treatment at $723 \mathrm{~K}$ for $30 \mathrm{~min}$ (alloy C).
The microstructure of alloy $\mathrm{C}$ is displayed in figure 2(c). The bright field image clearly reveals the presence of $5-15 \mathrm{~nm}$ sized nanocrystals in an amorphous matrix. The SAD pattern exhibits spots with varying intensity and size. In addition, a broad but faint halo can be observed that overlaps with the inner rings. Identification of the crystallographic structure of the nanocrystals was not possible.

\subsection{Thermal analysis}

Figure 3 shows a typical DSC trace scanned at a heating rate of $0.66 \mathrm{~K} \mathrm{~s}^{-1}$ for the different powders. For all the alloys A-C, the scans show an endothermic heat effect due to the glass transition followed by a wide supercooled liquid region before crystallization. The crystallization proceeds via two exothermic peaks in case of alloys A and B while there is only one exothermic peak for alloy $\mathrm{C}$. The onset $T_{\mathrm{g}}$ and onset $T_{\mathrm{x}}$ values for alloy $\mathrm{A}$ are $700 \mathrm{~K}$ and $762 \mathrm{~K}$ while those for alloy $\mathrm{B}$ are $703 \mathrm{~K}$ and $754 \mathrm{~K}$, respectively. The width of the supercooled liquid region $\left(\Delta T=T_{\mathrm{x}}-T_{\mathrm{g}}\right)$, is $62 \mathrm{~K}$ and $51 \mathrm{~K}$ for alloy $\mathrm{A}$ and alloy $\mathrm{B}$, respectively. In the case of alloy $\mathrm{C}, T_{\mathrm{g}}$ is $689 \mathrm{~K}$ and $T_{x}$ is $781 \mathrm{~K}$, resulting in a $\Delta T$ value of $92 \mathrm{~K}$. It has to be noted that these values are measured at a heating rate of $0.66 \mathrm{~K} \mathrm{~s}^{-1}$. The heating rate dependence of the characteristic temperatures reflects the kinetic mechanisms of the structural relaxation and the phase transformation in the glasses/supercooled liquids and these processes can be evaluated in terms of the fragility of supercooled liquids [19-21]. The fragility can be determined from the heating rate dependence of the calorimetric glass transition because the viscosity relaxation and the glass transition measured by calorimetry occur on the same time scale [47]. Hence, the fragility values of the alloys reflect the sensitivity of the liquid to temperature changes. Figure 4 shows the variation of the DSC traces at various heating rates for all the alloys. A distinct glass transition can be found at all heating rates.
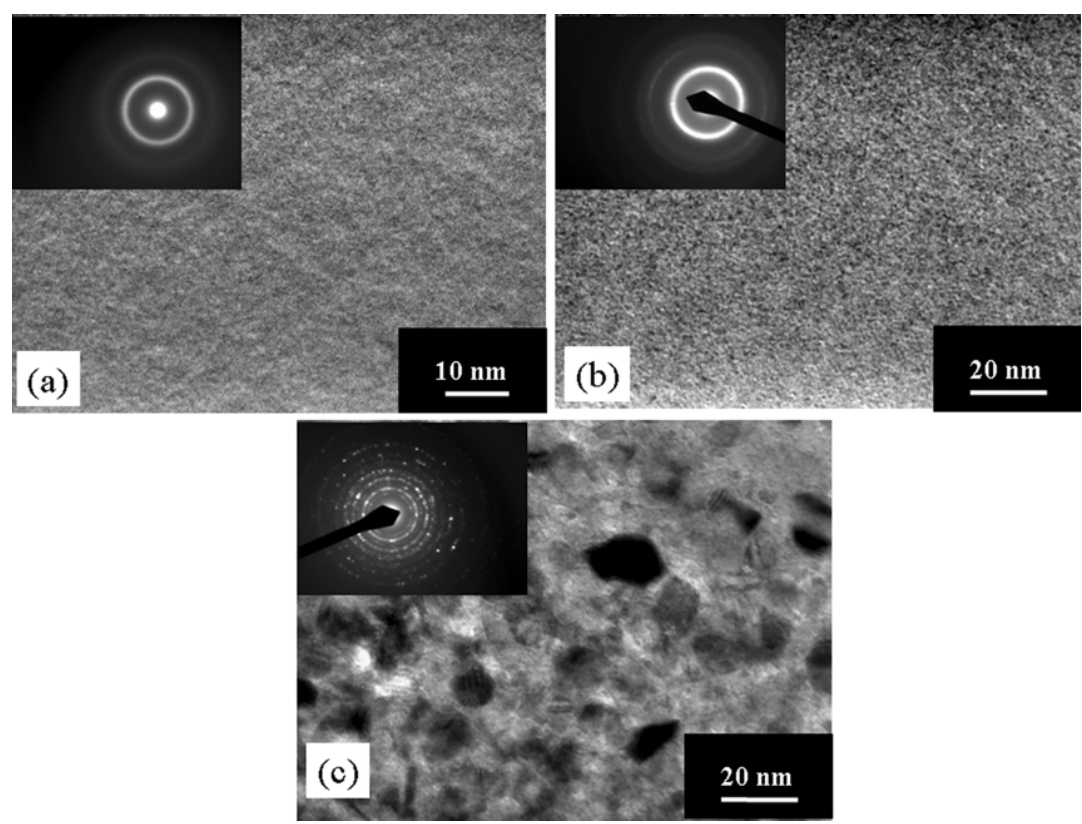

Figure 2. Bright-field TEM micrographs and SAD patterns (shown as inset) for the as-prepared and thermally treated $\mathrm{Cu}_{47} \mathrm{Ti}_{33} \mathrm{Zr}_{11} \mathrm{Ni}_{8} \mathrm{Si}_{1}$ powders. 


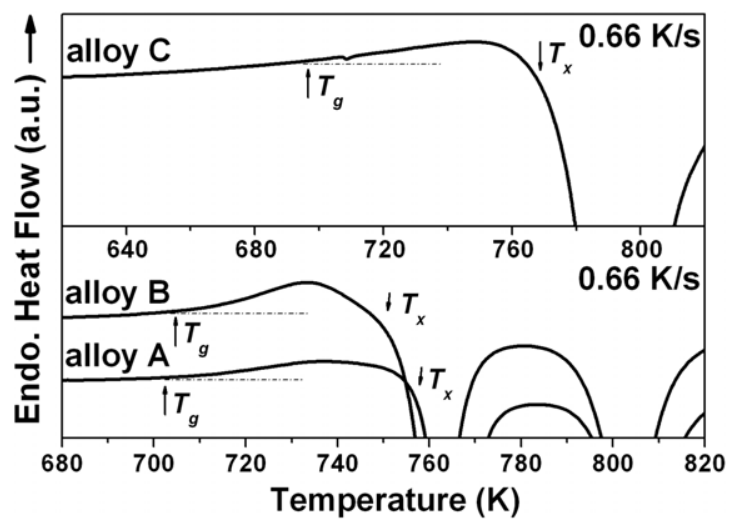

Figure 3. DSC traces $\left(0.66 \mathrm{~K} \mathrm{~s}^{-1}\right)$ for $\mathrm{Cu}_{47} \mathrm{Ti}_{33} \mathrm{Zr}_{11} \mathrm{Ni}_{8} \mathrm{Si}_{1}$ powders for alloys A, B and C.

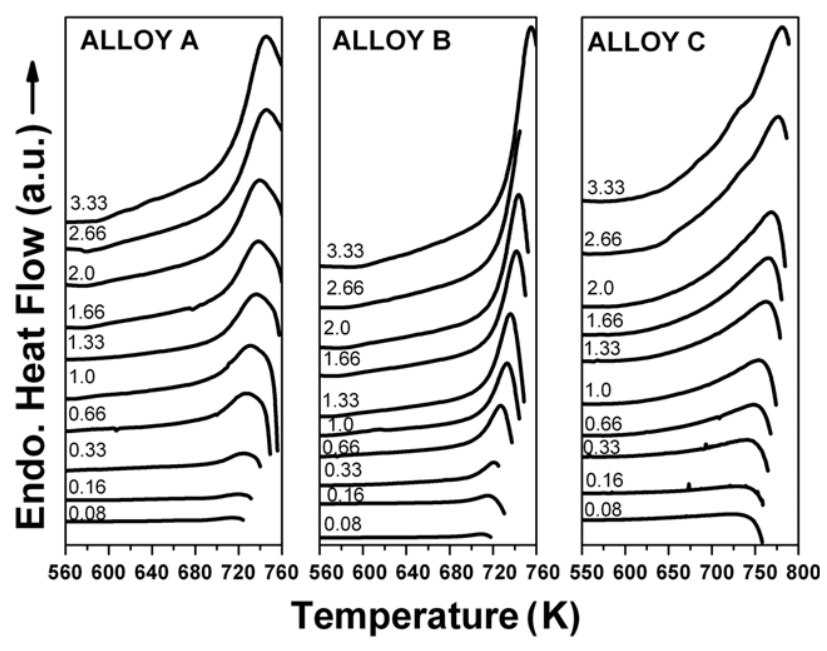

Figure 4. Isochronal DSC plots for all the alloys.

The dependence of the glass transition temperature, $T_{\mathrm{g}}$, on the heating rate, $\beta$, was evaluated in terms of the VFT equation written in the form [21]

$$
\beta\left(T_{\mathrm{g}}\right)=B \exp \left[D T_{\mathrm{g}}^{0} /\left(T_{\mathrm{g}}^{0}-T_{\mathrm{g}}\right)\right] .
$$

Here, $T_{\mathrm{g}}^{0}$ is the asymptotic value of $T_{\mathrm{g}}$, which is usually approximated as the onset of the glass transition at the limit of infinitely slow cooling, $B$ has the dimension of a heating rate and $D$ is the strength parameter. For the data analysis, the $T_{\mathrm{g}}$ corresponding to each heating rate $\left(0.08-3.33 \mathrm{~K} \mathrm{~s}^{-1}\right)$ was evaluated from the DSC scans recorded at these heating rates for all the alloys. The fitting of the experimental data was done using the equation

$$
\ln \beta\left(T_{\mathrm{g}}\right)=\ln B-\frac{D T_{\mathrm{g}}^{0}}{\left(T_{\mathrm{g}}-T_{\mathrm{g}}^{0}\right)}
$$

with three adjustable VFT parameters, $B, D$ and $T_{\mathrm{g}}^{0}$. The calculated values are given in table 1 and the best fits are shown by lines in figure 5. All the fit parameters show a decrease in magnitude with increasing annealing treatment. Generally, the fragility can be classified in terms of the strength parameter, $D$ (as in (2)) or by the fragility parameter $(m)$ defined as [48]

$$
m=\left.\frac{\mathrm{d} \log \langle\tau\rangle}{\mathrm{d}\left(T_{\mathrm{g}} / T\right)}\right|_{T=T_{\mathrm{g}}},
$$

Table 1. Thermal stability data and VFT parameters for the best fit of the DSC data according to equation (2). $T_{\mathrm{g}, 0.33}$ and $T_{\mathrm{g}, 0.66}$ refers to $T_{\mathrm{g}}$ measured at a heating rate of $0.33 \mathrm{~K} \mathrm{~s}^{-1}$ and $0.66 \mathrm{~K} \mathrm{~s}^{-1}$, respectively, $T_{x, 0.66}$ refers to $T_{\mathrm{x}}$ measured at a heating rate of $0.66 \mathrm{~K} \mathrm{~s}^{-1} . \Delta T_{0.66}=T_{x, 0.66}-T_{\mathrm{g}, 0.66}$ and $\ln B, D$ and $T_{\mathrm{g}}^{0}$ are VFT fit parameters.

\begin{tabular}{lllllllll}
\hline Alloy & $T_{\mathrm{g}, 0.66}$ & $T_{x, 0.66}$ & $\Delta T_{0.66}$ & $\ln B$ & $D$ & $T_{\mathrm{g}}^{0}$ & $T_{\mathrm{g}, 0.33}$ & $m$ \\
\hline A & 700 & 762 & 62 & 5 & 0.42 & 652 & 696 & 44 \\
B & 703 & 754 & 51 & 4 & 0.40 & 648 & 696 & 35 \\
C & 689 & 781 & 92 & 3 & 0.36 & 621 & 680 & 19 \\
\hline
\end{tabular}

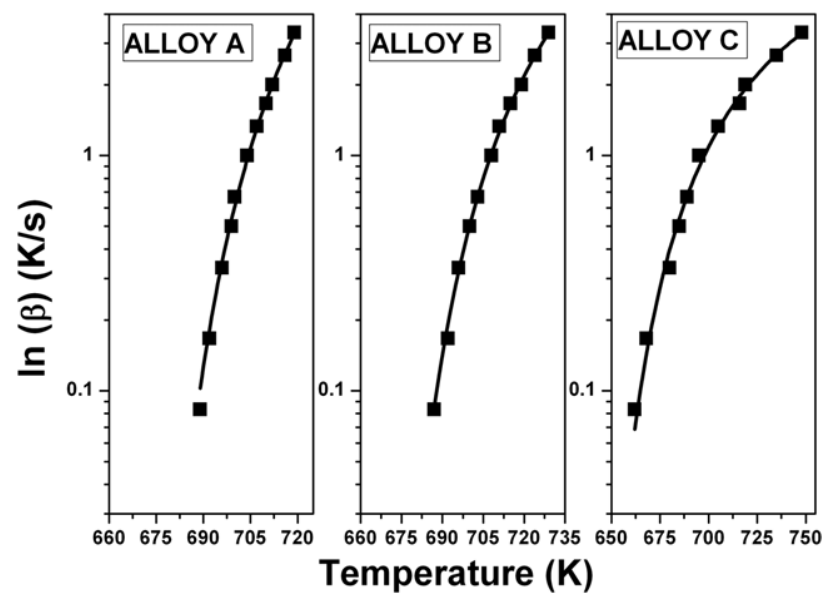

Figure 5. Glass transition temperature as a function of the applied heating rate and the VFT fit for the as-prepared and isothermally treated $\mathrm{Cu}_{47} \mathrm{Ti}_{33} \mathrm{Zr}_{11} \mathrm{Ni}_{8} \mathrm{Si}_{1}$ alloy powders.

where $T$ is the temperature, $T_{\mathrm{g}}$ the glass transition and $\langle\tau\rangle$ is the average relaxation time. From the VFT fits the fragility parameter $(m)$ at a particular $T_{\mathrm{g}}$ can be calculated as in equation (4) [49]:

$$
m=\frac{D T_{\mathrm{g}}^{0} T_{\mathrm{g}}}{\left(T_{\mathrm{g}}-T_{\mathrm{g}}^{0}\right)^{2} \ln 10} .
$$

It is obvious from equation (4) that the value of $m$ depends on the definition of $T_{\mathrm{g}}$. In order to make a uniform comparison with fragility data found in the literature, $m$ has been evaluated at $T_{\mathrm{g}}$ corresponding to a heating rate of $0.33 \mathrm{~K} \mathrm{~s}^{-1}$. The $m$ values are also listed in table 1 . In the case of alloy A the $m$ value is 44 while for alloys B and C it is 35 and 19, respectively. This reveals that the fragility parameter changes with increasing annealing temperature. There are three key temperatures that are widely used to characterize the vitrification of a supercooled liquid: glass transition temperature $\left(T_{\mathrm{g}}\right)$, Vogel-Fulcher temperature $\left(T_{0}=\right.$ $T_{\mathrm{g}}^{0}$, as in (4)) and the Kauzmann temperature $\left(T_{\mathrm{K}}\right)$ [50]. $T_{\mathrm{g}}^{0}$ and $T_{\mathrm{K}}$ refer to the kinetic and thermodynamic instability points, respectively [50]. The heating rate $(\beta)$ dependence of $T_{\mathrm{g}}$ and $T_{\mathrm{x}}$ is plotted by a linear fit for alloys $\mathrm{A}$ and $\mathrm{B}$ in figure 6 . The extrapolation of both curves to lower temperatures as well as heating rates leads to a point of intersection. The temperature that corresponds to this point of intersection has been reported to correspond to the Kauzmann temperature [51]. The $T_{\mathrm{K}}$ values are $645 \mathrm{~K}$ and $575 \mathrm{~K}$ for alloys $\mathrm{A}$ and $\mathrm{B}$, respectively. The $T_{\mathrm{K}}$ value for alloy $\mathrm{C}$ could not be determined due to very large errors involved in the extrapolation. 


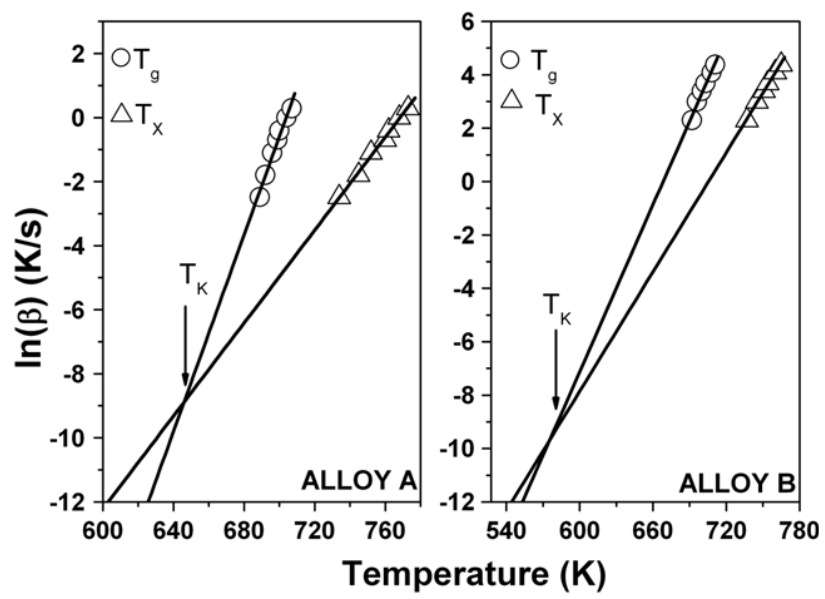

Figure 6. Glass transition temperature and onset temperature of the first crystallization exotherm as a linear function of applied heating rate for the as-prepared and isothermally treated $\mathrm{Cu}_{47} \mathrm{Ti}_{33} \mathrm{Zr}_{11} \mathrm{Ni}_{8} \mathrm{Si}_{1}$ alloy powders. The point of intersection is the Kauzmann temperature $\left(T_{\mathrm{K}}\right)$.

\section{Discussion}

The XRD as well as the TEM data for alloy A clearly indicate that the as-prepared powder is fully amorphous. Additionally, the DSC trace of alloy A clearly reveals a distinct glass transition. The thermal stability data of this alloy are in good agreement with previously reported data [42-44]. The purpose of the annealing experiments has been to study the influence of thermal treatment undertaken at temperatures below $(688 \mathrm{~K}$ for $60 \mathrm{~min}$ ) and above ( $723 \mathrm{~K}$ for $30 \mathrm{~min})$ the experimentally observed glass transition temperature $(700 \mathrm{~K}$ at a heating rate of $0.66 \mathrm{~K} \mathrm{~s}^{-1}$ ) and to study its effect on the fragility of the metallic glass powders. Since microstructural alterations are possible upon thermal treatment, the influence of microstructure on the fragility is also investigated. After annealing at $688 \mathrm{~K}$ for 60 min (alloy B) the XRD pattern gives no hint of the presence of sharp peaks related to any crystallinity. The bright-field TEM image shows no features indicating crystallization but the contrast observed could be due to variations in material density as well as thickness variations [52]. The thermal stability data for alloy B are also different from alloy A, indicating that the composition of the glass has indeed changed upon thermal treatment. A change in composition can lead to local density variations [52]. Additionally, the SAD pattern displays sharper rings and hence suggests an enhanced shortrange order upon thermal treatment and points to the beginning of crystallization. The TEM observations are very similar to observations reported for the $\mathrm{Zr}_{52} \mathrm{Ti}_{5} \mathrm{Cu}_{17.9} \mathrm{Ni}_{14.6} \mathrm{Al}_{10}$ metallic glass that was isothermally annealed near the glass transition [53]. In contrast, the TEM results for alloy $\mathrm{C}$ (figure 2(c)) clearly reveal the presence of nanocrystals in an amorphous matrix. This is also corroborated by the DSC trace of alloy C where the first exothermic event seen in the DSC traces of alloys A and B (figure 3) is eliminated. Surprisingly, the XRD pattern for alloy $\mathrm{C}$ (figure 1) also does not exhibit any diffraction peaks. A previous study on the crystallization of $\mathrm{Cu}_{47} \mathrm{Ti}_{33} \mathrm{Zr}_{11} \mathrm{Ni}_{8} \mathrm{Si}_{1}$ metallic glass powders has shown that the product of the first crystallization exotherm is the $\mathrm{Cu}_{51} \mathrm{Zr}_{14}$ phase with nanometer sized grains [54]. It has been reported
Table 2. GFA data of various glass-forming alloys having similar fragility parameter $(m)$ value. The data are taken from [56]

\begin{tabular}{lllll}
\hline Alloy composition & $\Delta T(\mathrm{~K})$ & $T_{\mathrm{rg}}$ & $R_{\mathrm{c}}\left(\mathrm{K} \mathrm{s}^{-1}\right)$ & $m$ \\
\hline $\mathrm{Fe}_{30.8} \mathrm{Co}_{46.2} \mathrm{P}_{14} \mathrm{~B}_{6} \mathrm{Al}_{3}$ & 38 & - & $\sim 10^{3}$ & 43 \\
$\mathrm{Pd}_{48} \mathrm{Ni}_{32} \mathrm{P}_{20}$ (non-fluxed) & 89 & 0.67 & $\sim 10^{3}$ & 41 \\
$\mathrm{Pd}_{40} \mathrm{Ni}_{40} \mathrm{P}_{20}$ (non-fluxed) & 88 & 0.67 & $\sim 10^{3}$ & 41 \\
$\mathrm{Pt}_{45} \mathrm{Ni}_{30} \mathrm{P}_{25}$ & 56 & 0.67 & $\sim 10^{3}$ & 42 \\
$\mathrm{Cu}_{47} \mathrm{Ti}_{33} \mathrm{Zr}_{11} \mathrm{Ni}_{8} \mathrm{Si}_{1}$ & 62 & 0.60 & $\sim 70$ & 44 \\
$\mathrm{Co}_{62} \mathrm{Nb}_{6} \mathrm{Zr}_{2} \mathrm{~B}_{30}$ & 50 & 0.63 & - & 44 \\
$\mathrm{Co}_{46} \mathrm{Fe}_{16} \mathrm{Nb}_{6} \mathrm{Zr}_{2} \mathrm{~B}_{30}$ & 88 & 0.63 & - & 44 \\
\hline
\end{tabular}

by Jiang et al by a simulation study that the $\mathrm{Cu}_{51} \mathrm{Zr}_{14}$ phase, when formed with small grain size $(8-15 \mathrm{~nm})$ and defects, shows a broadened amorphous-like feature [55]. Additionally, it has been shown by XRD/high-resolution TEM (HRTEM) studies in case of the $\mathrm{Zr}_{54.5} \mathrm{Ti}_{7.5} \mathrm{Cu}_{20} \mathrm{Ni}_{8} \mathrm{Al}_{10}$ quasicrystalforming alloy that though there is a decrease in FWHM by $10 \%$, there is a particle size effect for the non-detectable XRD peaks of quasicrystals [56]. Hence, it is not surprising that the diffraction pattern of alloy $\mathrm{C}$ shows an amorphous-like feature.

The fragile/strong behaviour of the supercooled liquid can be classified by the fragility parameter $(m)[19,20]$. Open network liquids or strong liquids like $\mathrm{SiO}_{2}$ and $\mathrm{GeO}_{2}$ show an Arrhenius-type temperature dependence and exhibit $m$ values in the range of $16 \leqslant m \leqslant 30[19,20]$. In contrast, fragile liquids, such as ionic melts and polymers, which are characterized by simple nondirectional Coulomb attractions or by Van der Waals interactions, exhibit large values $(m \geqslant 100)[19,20]$. Metallic glassy alloys typically have $m$ values in the range of $32 \leqslant m \leqslant 66$ and, hence, can be classified in the intermediate category according to Angell's classification scheme [57]. Alloy A with $m=44$ lies in the area closer to the strong side in the Angell plot. A previous study on the melt fragility of the $\mathrm{Cu}_{47} \mathrm{Ti}_{34} \mathrm{Zr}_{11} \mathrm{Ni}_{8}$ glass-forming alloy gave a $m$ value of $59[30,45]$. Hence, it is clear that the addition of 1 at.\% Si renders the supercooled liquid stronger in the Angell classification. It was shown that the $\mathrm{Cu}_{50} \mathrm{Zr}_{50}$ BMG has a fragility parameter of 62 [31]. Accordingly, alloy A is a stronger liquid compared with $\mathrm{Cu}_{50} \mathrm{Zr}_{50}$. The $m$ value of 44 is comparable to that of $\mathrm{Fe}_{30.8} \mathrm{Co}_{46.2} \mathrm{P}_{14} \mathrm{~B}_{6} \mathrm{Al}_{3}(m=43)$ [58] as well as to that of the well-known $\mathrm{Pd}_{48} \mathrm{Ni}_{32} \mathrm{P}_{20}, \mathrm{Pd}_{40} \mathrm{Ni}_{40} \mathrm{P}_{20}(m=41)$ [58] and $\mathrm{Pt}_{45} \mathrm{Ni}_{30} \mathrm{P}_{25}(m=42)$ [59] metallic glasses, but smaller than that of $\mathrm{Pd}_{40} \mathrm{Cu}_{30} \mathrm{Ni}_{10} \mathrm{P}_{20}(m=52)$ [60], $\mathrm{Ni}_{75} \mathrm{P}_{16} \mathrm{~B}_{6} \mathrm{Al}_{3}$ $(m=53)$ [58] and $\mathrm{Au}_{76.9} \mathrm{Ge}_{13.65} \mathrm{Si}_{9.45}(m=60)$ [61, 62]. However, the $m$ value is larger than for $\mathrm{Zr}_{65} \mathrm{Cu}_{17.5} \mathrm{Ni}_{10} \mathrm{Al}_{7.5}$ $(m=35)$ [63], $\mathrm{Zr}_{41.2} \mathrm{Ti}_{13.8} \mathrm{Cu}_{12.8} \mathrm{Ni}_{10} \mathrm{Be}_{22.5}(m=39)$ [64], $\mathrm{Zr}_{46.75} \mathrm{Ti}_{8.25} \mathrm{Cu}_{7.5} \mathrm{Ni}_{10} \mathrm{Be}_{27.5}(m=18)$ [34] and $\mathrm{Pr}-\mathrm{Cu}-\mathrm{Ni}-$ Al $(m=31)$ [27] metallic glasses. Table 2 lists the GFA parameters of numerous metallic glasses having more or less the same fragility parameter as alloy A. Though the $m$ value for alloy $\mathrm{A}$ is similar to $\mathrm{Pd}_{48} \mathrm{Ni}_{32} \mathrm{P}_{20}$ and $\mathrm{Pt}_{45} \mathrm{Ni}_{30} \mathrm{P}_{25}$ metallic glasses, $\mathrm{Pd}_{48} \mathrm{Ni}_{32} \mathrm{P}_{20}$ can be formed in bulk form only after fluxing the melt in molten $\mathrm{B}_{2} \mathrm{O}_{3}$ over several thermal cycles [65] and $\mathrm{Pt}_{45} \mathrm{Ni}_{30} \mathrm{P}_{25}$ has so far not been quenched into a bulk glass. From table 2 it is clear that there is no general correlation between the $m$ value and $\Delta T$ as well as with $T_{\mathrm{rg}}$. There seems to be also no correlation between $m$ and the critical cooling rate $\left(R_{\mathrm{c}}\right)$. Although the fragility parameter of all the alloys requiring critical cooling rates of the order of $10^{3} \mathrm{~K} \mathrm{~s}^{-1}$ 
Table 3. GFA data for various $\mathrm{Cu}$-based metallic glasses.

\begin{tabular}{lllcl}
\hline Alloy composition & $\Delta T(\mathrm{~K})$ & $T_{\mathrm{rg}}$ & $R_{\mathrm{c}}\left(\mathrm{K} \mathrm{s}^{-1}\right)$ & $m$ \\
\hline $\mathrm{Cu}_{50} \mathrm{Zr}_{50}$ & 47 & 0.55 & 250 & 62 \\
$\mathrm{Cu}_{47} \mathrm{Ti}_{34} \mathrm{Zr}_{11} \mathrm{Ni}_{8}$ & 46 & 0.57 & $\sim 250$ & 59 \\
$\mathrm{Cu}_{47} \mathrm{Ti}_{33} \mathrm{Zr}_{11} \mathrm{Ni}_{8} \mathrm{Si}_{1}$ & 62 & 0.60 & $\sim 70$ & 44 \\
\hline
\end{tabular}

is $41-44$, it does not explain the ease of glass formation in the many metallic glass compositions. For example, $R_{\mathrm{c}}$ for $\mathrm{Pd}_{40} \mathrm{Cu}_{30} \mathrm{Ni}_{10} \mathrm{P}_{20}(m=52), \mathrm{Zr}_{46.75} \mathrm{Ti}_{8.25} \mathrm{Cu}_{7.4} \mathrm{Ni}_{10} \mathrm{Be}_{27.5}$ ( $m=34$ ) and $\mathrm{Mg}_{65} \mathrm{Cu}_{25} \mathrm{Y}_{10}(m=41)$ is $0.1 \mathrm{~K} \mathrm{~s}^{-1}$ [66], $30 \mathrm{~K} \mathrm{~s}^{-1}$ [9] and $50 \mathrm{~K} \mathrm{~s}^{-1}$ [22], respectively. It has been shown that the $\mathrm{Pd}_{43} \mathrm{Ni}_{10} \mathrm{Cu}_{27} \mathrm{P}_{20}$ composition is a very good glass former and has a critical cooling rate as low as $0.01 \mathrm{~K} \mathrm{~s}^{-1}$ [67]. However, the fragility parameter is 65 for this alloy. Not only the $m$ parameter but also the lower driving force for crystal nucleation as well as the diffusion lengths necessary for primary crystallization in the $\mathrm{Pd}_{43} \mathrm{Ni}_{10} \mathrm{Cu}_{27} \mathrm{P}_{20}$ alloy are influencing factors in determining the excellent GFA of this alloy [67]. Hence, the fragility index itself can only give a rough estimate of the GFA but the GFA also depends on the thermodynamics of the system.

However, there seems to be a decent trend in case of $\mathrm{Cu}$ based metallic glasses. Table 3 shows the GFA parameters for the $\mathrm{Cu}$-based metallic glasses. It was mentioned that $R_{\mathrm{c}}$ of $\mathrm{Cu}_{50} \mathrm{Zr}_{50}(m=62)$ [31] as well as of the $\mathrm{Cu}_{47} \mathrm{Ti}_{34} \mathrm{Zr}_{11} \mathrm{Ni}_{8}$ ( $m=59$ ) glass is $250 \mathrm{~K} \mathrm{~s}^{-1}$ [32]. The present study gives a $m$ value for $\mathrm{Cu}_{47} \mathrm{Ti}_{33} \mathrm{Zr}_{11} \mathrm{Ni}_{8} \mathrm{Si}_{1}$ of 44 . It was shown that the addition of 1 at.\% $\mathrm{Si}$ increases the GFA (i.e. increases $\Delta T$ and decreases $R_{\mathrm{c}}$ ) [42]. $R_{\mathrm{c}}$ decreases by a factor of 3 and the critical casting thickness can be increased by a factor of 1.7 for the alloy containing $\mathrm{Si}$ vis-a-vis the alloy without $\mathrm{Si}$ [42]. A similar trend has been found in case of the $\mathrm{Zr}-\mathrm{Cu}-$ $\mathrm{Ti}-\mathrm{Ni}-\mathrm{Be}$ alloy system. For $\mathrm{Zr}_{46.75} \mathrm{Ti}_{8.25} \mathrm{Cu}_{7.5} \mathrm{Ni}_{10} \mathrm{Be}_{27.5}$, the $m$ value is 34 [47]. When the composition is slightly changed to $\mathrm{Zr}_{41.2} \mathrm{Ti}_{13.8} \mathrm{Cu}_{12.5} \mathrm{Ni}_{10} \mathrm{Be}_{22.5}$ the $m$ value obtained is 39 [64] and $m=31$ for $\mathrm{Zr}_{42.1} \mathrm{Ti}_{12.9} \mathrm{Cu}_{11.5} \mathrm{Ni}_{10.2} \mathrm{Be}_{23.3}$ [68]. Hence, summarizing the results from tables 2 and 3 it can be said that the idea that 'a lower $m$ value essentially means a higher GFA in terms of a higher $T_{\mathrm{rg}}$ value and a lower $R_{\mathrm{c}}$ ' holds true only for metallic glasses of a particular family of metallic glasses and cannot be generalized for all glass-forming alloys. The tables also possibly provide a hint that the viscosity is rather material-specific and not a primary factor causing differences in the GFA among these liquids and thermodynamic factors are possibly very important. It has been empirically established that the relation $T_{\mathrm{K}} \cong T_{\mathrm{g}}^{0}$ holds for many glass-forming liquids [69]. The $T_{\mathrm{K}} / T_{\mathrm{g}}^{0}$ ratio is 0.99 and 0.89 for alloys $\mathrm{A}$ and $\mathrm{B}$, respectively. It was reported by Tanaka [50] that the higher the $T_{\mathrm{K}} / T_{\mathrm{g}}^{0}$ ratio the stronger is the glass. However, it needs to be mentioned that the existence of such a correlation depends critically on how the thermodynamic fragility is evaluated. Conventionally, the entropy is normalized by the value at the melting point or by the value at the glass transition temperature [69, 70]. A study by Fan et al [71] proposed an alternate way of defining the thermodynamic fragility. It was suggested that the quantity $\Delta S_{\mathrm{f}} /\left(T_{\mathrm{m}}-T_{\mathrm{K}}\right)$, where $\Delta S_{\mathrm{f}}$ is the entropy of fusion and $T_{\mathrm{m}}$ is the melting temperature, can adequately define the thermodynamic fragility. Since our alloy has a composition very close to that of $\mathrm{Cu}_{47} \mathrm{Ti}_{34} \mathrm{Zr}_{11} \mathrm{Ni}_{8}$ whose $\Delta S_{\mathrm{f}}=10.1 \mathrm{~J} \mathrm{~mol}^{-1}$ [72], and $T_{\mathrm{m}}=1170 \mathrm{~K}$, this ratio is found to be 0.0192 and 0.0161 for alloys $\mathrm{A}$ and $\mathrm{B}$, respectively. The smaller the value of $\Delta S_{\mathrm{f}} /\left(T_{\mathrm{m}}-T_{\mathrm{K}}\right)$ the more thermodynamically strong is the liquid [71]. Hence, alloy B is stronger than alloy A. This finding is in accordance with the $m$ values of 44 and 35 obtained for alloys A and B, respectively. The $\mathrm{m}$ values are a measure of the kinetic fragility. Hence, it can be said that there exists a relation between the thermodynamic and kinetic fragility. Indeed, it has been shown that there exists a close relation between kinetics and thermodynamics in the determination of the fragility of metallic glass-forming liquids [73, 74]. However, a recent detailed study by Battezzatti [45] has reported that although there exists such a link it is not necessarily proved given the uncertainities in thermodynamic data. Hence, it is logical to say that both the kinetic and thermodynamic contributions play essential roles in the fragility of glass-forming alloys.

With increasing thermal treatment temperature, the fragility parameter of $\mathrm{Cu}_{47} \mathrm{Ti}_{33} \mathrm{Zr}_{11} \mathrm{Ni}_{8} \mathrm{Si}_{1}$ powders (alloys B and $\mathrm{C}$ ) shifts to lower values and shifts more towards the side of the strong liquids according to Angell's classification. This can be explained on the basis of the crystallization behaviour of the $\mathrm{Cu}_{47} \mathrm{Ti}_{33} \mathrm{Zr}_{11} \mathrm{Ni}_{8} \mathrm{Si}_{1}$ metallic glass. Metallic glasses crystallize by a nucleation and growth process [75]. It has been shown that $\mathrm{Cu}_{47} \mathrm{Ti}_{33} \mathrm{Zr}_{11} \mathrm{Ni}_{8} \mathrm{Si}_{1}$ exhibits multistep crystallization behaviour [76]. The crystallization of this alloy starts with the primary precipitation of $\mathrm{Cu}_{51} \mathrm{Zr}_{14}$ crystals [54]. Primary crystallization results in the formation of a crystalline phase with an essentially different composition than the starting glass [77]. Alloy B has been annealed below the experimentally measured glass transition of alloy $\mathrm{A}$ while alloy $\mathrm{C}$ was thermally treated above the experimentally determined $T_{\mathrm{g}}$. It is well known that crystallization of metallic glasses can occur at temperatures above and below the glass transition temperature [78]. More recently, it has been shown that the crystallization of $\mathrm{Cu}_{47} \mathrm{Ti}_{33} \mathrm{Zr}_{11} \mathrm{Ni}_{8} \mathrm{Si}_{1}$ glassy powders occurs heterogeneously at temperatures below $T_{\mathrm{g}}$ by the growth of quenched-in nuclei while it occurs homogeneously at temperatures above $T_{\mathrm{g}}$ [79]. From our DSC measurements it is clear that the isothermal treatments done for alloy $\mathrm{B}$ and $\mathrm{C}$ change the values of $T_{\mathrm{g}}$ and $T_{\mathrm{x}}$ as compared with alloy A. The change is rather marginal in the case of alloy B ( $T_{\mathrm{g}}$ changes by $3 \mathrm{~K}$ and $T_{\mathrm{x}}$ by $8 \mathrm{~K}$ ) but more pronounced in the case of alloy $\mathrm{C}\left(T_{\mathrm{g}}\right.$ changes by $11 \mathrm{~K}$ and $T_{\mathrm{x}}$ by $\left.19 \mathrm{~K}\right)$. Additionally, the isothermal treatment of alloy $\mathrm{C}$ results in the formation of nanocrystals embedded in an amorphous matrix. This suggests that the remaining glassy matrix changes its composition under isothermal conditions. The VFT fit of alloy C (figure 5) describes essentially the steepness of the viscosity curve of the amorphous matrix and reveals that after primary crystallization the matrix is a stronger liquid than the homogeneous $\mathrm{Cu}_{47} \mathrm{Ti}_{33} \mathrm{Zr}_{11} \mathrm{Ni}_{8} \mathrm{Si}_{1}$ alloy (alloy A). An earlier report on the fragility data of $\mathrm{Zr}_{41.2} \mathrm{Ti}_{13.8} \mathrm{Cu}_{12.5} \mathrm{Ni}_{10} \mathrm{Be}_{22.5}$ clearly showed that the fragility parameter as well as the $T_{\mathrm{g}}^{0}$ value change significantly after primary crystallization [64]. The fragility parameter of the remaining supercooled liquid shifts to the stronger side while $T_{\mathrm{g}}^{0}$ shifts to lower values [64]. This suggests that the equilibrium (metastable equilibrium) viscosity value has indeed changed for the matrix (alloy $\mathrm{C}$ ) towards a higher value. This viscosity change is essentially 
caused by changes in the concentration of the matrix towards a composition with a higher viscosity at a given annealing temperature. The lower value of $m$ (i.e. stronger liquid) can be also linked to an increased short-range ordering of the amorphous phase in the case of alloy C. For example, a positive correlation between icosahedral ordering, well known in metallic glasses, and the fragility index has been found $[47,50]$. It has been shown that the $m$ value is more dependent on the structural gradient between neighbouring clusters $(\delta)$ and the activation energy difference $(\Delta E)$ for a system to change from one minimum to the neighbouring minimum in a multidimensional energy landscape [73]. However, further studies seem to be necessary to validate this correlation in a more quantitative way.

\section{Conclusion}

The thermal stability of $\mathrm{Cu}_{47} \mathrm{Ti}_{33} \mathrm{Zr}_{11} \mathrm{Ni}_{8} \mathrm{Si}_{1}$ glassy powders synthesized by gas-atomization has been evaluated in terms of the fragility parameter $(m)$ using the VFT relation based on the glass transition temperature determined on the basis of isochronal DSC runs. The fragility parameter is 44 in the asprepared state and decreases to a value of 19 for a partially crystallized powder. This indicates that $\mathrm{Cu}_{47} \mathrm{Ti}_{33} \mathrm{Zr}_{11} \mathrm{Ni}_{8} \mathrm{Si}_{1}$ behaves more like a strong glass. This implies sluggish kinetics and hence contributes to the GFA. The shift of the $m$ value towards a stronger liquid stems from the changed composition of the remaining supercooled liquid. In the case of $\mathrm{Cu}$-based metallic glasses, a lower $m$ value is essentially indicative of a reduced $R_{\mathrm{c}}$. The fragility of a metallic glass is linked not only to kinetic factors but also to thermodynamic ones.

\section{Acknowledgments}

We thank L Battezzati for sharing his recent work on fragility. The authors are grateful to J Das, I Kinski and S Scudino for stimulating discussions and $\mathrm{H}$ S Jeevan and C Mickel for microstructural investigations. Funding for this work was provided by the German Research Foundation under grant no. Ec 111/10 as well as by the European Union within the framework of the Research Training Network on 'ductile bulk metallic glass composites' (MRTN-CT-2003504692). Synthesis efforts by DJS were supported by the US Department of Energy, Basic Energy Sciences, through Iowa State University under Contract No W-7405-ENG-82.

\section{References}

[1] Chen H S 1980 Glassy metals Rep. Prog. Phys. 43 353-432

[2] Luborsky F E 1983 Amorphous metallic alloys Amorphous Metallic Alloys ed F E Luborsky (London: Butterworth) pp 1-7

[3] Herlach D M and Willnecker R 1993 Undercooling and solidification Rapidly Solidified Alloys Processes Structures Properties Applications ed H H Liebermann (New York: Marcel Dekker) pp 79-102

[4] Inoue A 1995 High strength bulk amorphous alloys with low critical cooling rates Mater. Trans., JIM. 36 866-75

[5] Inoue A 2000 Stabilization of metallic supercooled liquid and bulk amorphous alloys Acta Mater. 48 279-306

[6] Davies H A 1983 Metallic glass formation Amorphous Metallic Alloys ed F E Luborsky (London: Butterworth) pp 8-25
[7] Li Y, Ng S C, Ong C K, Hng H H and Goh T T 1997 Glass forming ability of bulk glass forming alloys Scr. Mater. 36 783-87

[8] Spaepen F and Turnbull D 1984 Metallic glasses Annu. Rev. Phys. Chem. 35 241-63

[9] Waniuk T A, Schroers J and Johnson W L 2001 Critical cooling rate and thermal stability of $\mathrm{Zr}-\mathrm{Ti}-\mathrm{Cu}-\mathrm{Ni}-\mathrm{Be}$ alloys Appl. Phys. Lett. 78 1213-15

[10] Shen T D, He Y and Schwarz R B 1999 Bulk amorphous $\mathrm{Pd}-\mathrm{Ni}-\mathrm{Fe}-\mathrm{P}$ alloys: preparation and characterization J. Mater. Res. 14 2107-15

[11] Shen T D and Schwarz R B 1999 Bulk ferromagnetic glasses prepared by flux melting and water quenching Appl. Phys. Lett. 75 49-51

[12] Murty B S and Hono K 2000 Formation of nanocrystalline particles in glassy matrix in melt-spun $\mathrm{Mg}-\mathrm{Cu}-\mathrm{Y}$ based alloys Mater. Trans., JIM 41 1538-44

[13] Davies H A 1978 Proc. 3rd Int. Conf. on Rapidly Quenched Metals (Brighton) vol I, ed B Cantor (London: Metals Society) pp 1-21

[14] Hruby A 1972 Evaluation of glass-forming tendency by means of DTA Czech. J. Phys. B 22 1187-93

[15] Saad M and Poulain M 1987 Glass forming ability criterion Mater. Sci. Forum 19-20 11-18

[16] Lu Z P and Liu C T 2002 A new glass-forming ability criterion for bulk metallic glasses Acta Mater. 50 3501-12

[17] Chen Q J, Shen J, Fan H B, Sun J F, Huang Y J and McCartney D G 2005 Glass-forming ability of an iron based alloy enhanced by Co addition and evaluated by a new criterion Chin. Phys. Lett. 22 1736-8

[18] Park E S, Chang H J, Kim D H, Ohkubo T and Hono K 2006 Effect of substitution of $\mathrm{Ag}$ and $\mathrm{Ni}$ for $\mathrm{Cu}$ on the glass forming ability and plasticity of $\mathrm{Cu}_{60} \mathrm{Zr}_{30} \mathrm{Ti}_{10}$ alloy $S c r$ Mater. 54 1569-73

[19] Angell C A 1985 Spectroscopy simulation and scattering, and the medium range order in glass J. Non-Cryst. Solids $\mathbf{7 3}$ $1-17$

[20] Angell C A 1995 Formation of glasses from liquids and biopolymers Science 267 1924-35

[21] Brüning R and Samwer K 1992 Glass-transition on long-time scales Phys. Rev. B 46 11318-22

[22] Busch R, Liu W and Johnson W L 1998 Thermodynamics and kinetics of the $\mathrm{Mg}_{65} \mathrm{Cu}_{25} \mathrm{Y}_{10}$ bulk metallic glass forming liquid J. Appl. Phys. 83 4134-41

[23] Linderoth S, Pryds N H, Ohnuma M, Pedersen A S, Eldrup M, Nishiyama N and Inoue A 2001 On the stability and crystallization of bulk amorphous $\mathrm{Mg}-\mathrm{Cu}-\mathrm{Y}-\mathrm{Al}$ alloys Mater. Sci. Eng. A 304-306 656-9

[24] Mitrovic N, Roth S and Eckert J 2001 Kinetics of the glass-transition and crystallization process of $\mathrm{Fe}_{72-x} \mathrm{Nb}_{x} \mathrm{Al}_{5} \mathrm{Ga}_{2} \mathrm{P}_{11} \mathrm{C}_{6} \mathrm{~B}_{4}(x=0,2)$ metallic glasses Appl. Phys. Lett. 78 2145-7

[25] Borrego J M, Conde A, Roth S and Eckert J 2002 Glass-forming ability and soft magnetic properties of FeCoSiAlGaPCB amorphous alloys J. Appl. Phys. 92 2073-8

[26] Borrego J M, Conde C F, Conde A, Roth S, Grahl H, Ostwald A and Eckert J 2002 Glass-forming ability and crystallization behavior of $\mathrm{Co}_{62-x} \mathrm{Fe}_{x} \mathrm{Nb}_{6} \mathrm{Zr}_{2} \mathrm{~B}_{30}$ $(x=0,16)$ amorphous alloys with large supercooled liquid region J. Appl. Phys. 92 6607-11

[27] Zhao Z F, Zhang Z, Wen P, Pan M X, Zhao D Q, Wang W H and Wang W L 2003 A highly glass-forming alloy with low glass transition temperature Appl. Phys. Lett. 82 4699-701

[28] He G, Eckert J and Hagiwara M 2004 Glass-forming ability and crystallization behaviour of $\mathrm{Ti}-\mathrm{Cu}-\mathrm{Ni}-\mathrm{Sn}-\mathrm{M}$ ( $\mathrm{M}=\mathrm{Zr}$, Mo and Ta) metallic glasses J. Appl. Phys. 95 1816-21

[29] Shadowspeaker L and Busch R 2004 On the fragility of $\mathrm{Nb}-\mathrm{Ni}$-based and Zr-based bulk metallic glasses Appl. Phys. Lett. 85 2508-10 
[30] Glade S C and Johnson W L 2000 Viscous flow of the $\mathrm{Cu}_{47} \mathrm{Ti}_{34} \mathrm{Zr}_{11} \mathrm{Ni}_{8}$ glass forming alloy J. Appl. Phys. 87 7249-51

[31] Tang M B, Zhao D Q, Pan M X and Wang W H 2004 Binary $\mathrm{Cu}-\mathrm{Zr}$ bulk metallic glasses Chin. Phys. Lett. 21 901-3

[32] Lin X H and Johnson W L 1995 Formation of T- $\mathrm{Zr}-\mathrm{Cu}-\mathrm{Ni}$ bulk metallic glasses J. Appl. Phys. 78 6514-19

[33] Zhang T and Inoue A 1999 Preparation of Ti-Cu-Ni-Si-B amorphous alloys with a large supercooled liquid region Mater. Trans., JIM 40 301-6

[34] Park E S, Lim H K, Kim W T and Kim D H 2002 The effect of $\mathrm{Sn}$ addition on the glass-forming ability of $\mathrm{Cu}-\mathrm{Ti}-\mathrm{Zr}-\mathrm{Ni}-\mathrm{Si}$ metallic glass alloys J. Non-Cryst. Solids 298 15-22

[35] Inoue A, Zhang W, Zhang T and Kurosaka K 2001 High-strength $\mathrm{Cu}$-based bulk glassy alloys in $\mathrm{Cu}-\mathrm{Zr}-\mathrm{Ti}$ and $\mathrm{Cu}-\mathrm{Hf}-\mathrm{Ti}$ ternary systems Acta Mater. 49 2645-52

[36] Park E S, Kim D H, Ohkubo T and Hono K 2005 Enhancement of glass forming ability and plasticity by addition of $\mathrm{Nb}$ in $\mathrm{Cu}-\mathrm{Ti}-\mathrm{Zr}-\mathrm{Ni}-\mathrm{Si}$ bulk metallic glasses J. Non-Cryst. Solids 351 1232-8

[37] Das J, Tang M B, Kim K B, Theissmann R, Baier F, Wang W H and Eckert J 2004 'Work-hardenable' ductile bulk metallic glass Phys. Rev. Lett. 94 205501-4

[38] Wang D, Li Y, Sun B B, Sui M L, Lu K and Ma E 2004 Bulk metallic glass formation in the binary $\mathrm{Cu}-\mathrm{Zr}$ system Appl. Phys. Lett. 84 4029-31

[39] Xu D H, Lohwongwatana B, Duan G, Johnson W L and Garland C 2004 Bulk metallic glass formation in binary Cu-rich alloy series- $\mathrm{Cu}_{100-x} \mathrm{Zr}_{x}(x=34,36,38.2$, 40 at.\%) and mechanical properties of bulk $\mathrm{Cu}_{64} \mathrm{Zr}_{36}$ glass Acta Mater. 52 2621-4

[40] Wang W H, Lewandowski J J and Greer A L 2005 Understanding the glass-forming ability of $\mathrm{Cu}_{50} \mathrm{Zr}_{50}$ alloys in terms of a metastable eutectic J. Mater. Res. 20 2307-13

[41] Zhang W and Inoue A 2006 High-glass forming ability and good mechanical properties of new bulk glassy alloys in $\mathrm{Cu}-\mathrm{Zr}-\mathrm{Ag}$ ternary system J. Mater. Res. 21 234-41

[42] Choi-Yim H, Busch R and Johnson W L 1998 The effect of silicon on the glass forming ability of the $\mathrm{Cu}_{47} \mathrm{Ti}_{34} \mathrm{Zr}_{11} \mathrm{Ni}_{8}$ bulk metallic glass forming alloy during processing of composites J. Appl. Phys. 83 7993-7

[43] Calin M, Stoica M, Eckert J, Schultz L and Yavari A R 2005 Glass formation and crystallization of $\mathrm{Cu}_{47} \mathrm{Ti}_{33} \mathrm{Zr}_{11} \mathrm{Ni}_{8} \mathrm{X}_{1}$ $(\mathrm{X}=\mathrm{Fe}, \mathrm{Si}, \mathrm{Sn}, \mathrm{Pb})$ alloys Mater. Sci. Eng. A 392 169-78

[44] Venkataraman S, Stoica M, Scudino S, Gemming T, Mickel C, Kunz U, Kim K B, Schultz L and Eckert J 2006 Revisiting the $\mathrm{Cu}_{47} \mathrm{Ti}_{33} \mathrm{Zr}_{11} \mathrm{Ni}_{8} \mathrm{Si}_{1}$ glass-forming alloy Scripta Mater. $54835-40$

[45] Battezzati L 2005 Is there a link between melt fragility and elastic properties of metallic glasses? Mater. Trans., JIM 46 2915-9

[46] Materials Preparation Center, Ames Laboratory, US-DOE, Ames, IA, USA, www.mpc.ameslab.gov

[47] Busch R, Bakke E and Johnson W L 1998 Viscosity of the supercooled liquid and relaxation at the glass transition of the $\mathrm{Zr}_{46.75} \mathrm{Ti}_{8.25} \mathrm{Cu}_{7.5} \mathrm{Ni}_{10} \mathrm{Be}_{27.5}$ bulk metallic glass forming alloy Acta Mater. 46 4725-32

[48] Bohmer R and Angell C A 1992 Correlations of the nonexponentiality and state dependence of mechanical relaxations with bond connectivity in $\mathrm{Ge}-\mathrm{As}-\mathrm{Se}$ supercooled liquids Phys. Rev. B 45 10091-4

[49] Bohmer R, Ngai K L, Angell C A and Plazek D J 1993 J. Chem. Phys. 99 4201-9

[50] Tanaka H 2003 Relation between thermodynamics and kinetics of glass-forming liquids Phys. Rev. Lett. 90 55701-4

[51] Busch R, Kim Y J and Johnson W L 1995 Thermodynamics and kinetics of the undercooled liquid and the glass transition of the $\mathrm{Zr}_{41.2} \mathrm{Ti}_{13.8} \mathrm{Cu}_{12.5} \mathrm{Ni}_{10} \mathrm{Be}_{22.5}$ J. Appl. Phys. 77 4039-43

[52] Williams D B and Carter C B 1996 Transmission Electron Microscopy, III, Imaging (New York: Plenum)
[53] Pekarskaya E, Löffler J F and Johnson W L 2003 Microstructural studies of crystallization of a $\mathrm{Zr}$-based bulk metallic glass Acta Mater. 51 4045-57

[54] Venkataraman S, Scudino S, Eckert J, Gemming T, Mickel C, Schultz L and Sordelet D J 2006 Nanocrystallization of gas atomized $\mathrm{Cu}_{47} \mathrm{Ti}_{33} \mathrm{Zr}_{11} \mathrm{Ni}_{8} \mathrm{Si}_{1}$ metallic glass J. Mater. Res. 21 597-607

[55] Jiang J Z, Kato H, Ohsuna T, Saida J, Inoue A, Saksl K, Franz H and Ståhl K 2003 Origin of nondetectable x-ray diffraction peaks in nanocomposite CuTiZr alloys Appl. Phys. Lett. 83 3299-301

[56] Xing L Q, Hufnagel T C, Eckert J, Löser W and Schultz L 2000 Relation between short-range order and crystallization behaviour in Zr-based amorphous alloys Appl. Phys. Lett. 77 1970-2

[57] Perera D N 1999 Compilation of the fragility parameters for several glass-forming metallic alloys J. Phys. Condens. Matter 11 3807-12

[58] Chen H S 1978 Alloying effect on viscous-flow in metallic glasses J. Non-Cryst. Solids $29223-9$

[59] Chen H S 1978 Method for evaluating viscosities of metallic glasses from rates of thermal transformations J. Non-Cryst. Solids 27 257-63

[60] Kato H, Kawamura Y, Inoue A and Chen H S 1998 Newtonian to non-Newtonian master flow curves of a bulk glassy alloy $\mathrm{Pd}_{40} \mathrm{Ni}_{10} \mathrm{Cu}_{30} \mathrm{P}_{20}$ Appl. Phys. Lett. 73 3665-7

[61] Chen H S and Turnbull D 1968 Evidence of a glass-liquid transition in a gold-germanium-silicon alloy J. Chem. Phys. 48 2560-71

[62] Polk D E and Turnbull D 1972 Flow of melt and glass forms of metallic alloys Acta Metall. 20 493-8

[63] Köster U, Meinhardt J, Roos S and Liebertz H 1996 Formation of quasicrystals in bulk glass forming $\mathrm{Zr}-\mathrm{Cu}-\mathrm{Ni}-\mathrm{Al}$ alloys Appl. Phys. Lett. 69 179-81

[64] Waniuk T A, Busch R, Masuhr A and Johnson W L 1998 Equilibrium viscosity of the $\mathrm{Zr}_{41.2} \mathrm{Ti}_{13.8} \mathrm{Cu}_{12.5} \mathrm{Ni}_{10} \mathrm{Be}_{22.5}$ bulk metallic glass-forming liquid and viscous flow during relaxation, phase separation, and primary crystallization Acta Mater. 46 5229-36

[65] He Y, Schwarz R B and Archuleta J I 1996 Bulk glass formation in the Pd-Ni-P system Appl. Phys. Lett. 69 $1861-3$

[66] Inoue A, Nishiyama N and Matsuda T 1996 Preparation of bulk glassy $\mathrm{Pd}_{40} \mathrm{Ni}_{10} \mathrm{Cu}_{30} \mathrm{P}_{20}$ alloy of $40 \mathrm{~mm}$ diameter by water quenching Mater. Trans., JIM. 37 181-4

[67] Fan G J, Löffler J F, Wunderlich R K and Fecht H-J 2004 Thermodynamics, enthalpy relaxation and fragility of the bulk metallic glass-forming liquid $\mathrm{Pd}_{43} \mathrm{Ni}_{10} \mathrm{Cu}_{27} \mathrm{P}_{20}$ Acta Mater. 52 667-74

[68] Perera D N and Tsai A P 2000 Thermal and viscoelastic properties of a strong bulk metallic glass former $J$. Phys. D: Appl. Phys. 33 1937-46

[69] Ito K, Moynihan C T and Angell C T 1999 Thermodynamic determination of fragility in liquids and a fragile-to-strong liquid transition in water Nature 398 492-5

[70] Martinez L M and Angell C A 2001 A thermodynamic connection to the fragility of glass-forming liquids Nature $410663-7$

[71] Fan G J, Choo H and Liaw P K 2005 Fragility of metallic glass-forming liquids: a simple thermodynamic connection J. Non-Cryst. Solids. 351 3879-83

[72] Glade S C, Busch R, Lee D S, Johnson W L, Wunderlich R K and Fecht $\mathrm{H} \mathrm{J} 2002$ Thermodynamics of $\mathrm{Cu}_{47} \mathrm{Ti}_{34} \mathrm{Zr}_{11} \mathrm{Ni}_{8}$, $\mathrm{Zr}_{52.5} \mathrm{Cu}_{17.9} \mathrm{Ni}_{14.6} \mathrm{Al}_{10} \mathrm{Ti}_{5}$ and $\mathrm{Zr}_{57} \mathrm{Cu}_{15.4} \mathrm{Ni}_{12.6} \mathrm{Al}_{10} \mathrm{Nb}_{5}$ bulk metallic glass forming alloys J. Appl. Phys. 87 7242-8

[73] Fan G J and Fecht H J 2002 A cluster model for the viscous flow of glass-forming liquids J. Chem. Phys. $1165002-6$

[74] Fan G J, Lavernia E J, Wunderlich R K and Fecht H J 2004 The relationship between thermodynamic and kinetic fragilities in metallic glass-forming liquids Philos. Mag. 84 2471-84 
[75] Scott M G 1983 Crystallization Amorphous Metallic Alloys ed F E Luborsky (London: Butterworth) pp 144-68

[76] Sordelet D J, Kramer M J, Besser M F and Rozhkova E 2001 Time resolved studies of $\mathrm{Ti}_{34-x} \mathrm{Cu}_{47} \mathrm{Zr}_{11} \mathrm{Ni}_{8} \mathrm{Si}_{x}$ metallic glass devitrification using high temperature $\mathrm{x}$-ray powder diffraction J. Non-Cryst. Solids. 290 163-72

[77] Köster U and Herold U 1981 Crystallization of metallic glasses Glassy Metals I ed H J Güntherodt and H Beck (Berlin: Springer) pp 225-59
[78] Köster U and Janlewing R 2004 Fragility parameter and nanocrystallization of metallic glasses Mater. Sci. Eng. A 375-377 223-6

[79] Venkataraman S, Löser W, Eckert J, Gemming T, Mickel C, Schubert-Bischoff P, Wanderka N, Schultz L and Sordelet D J 2006 Nanocrystal development in $\mathrm{Cu}_{47} \mathrm{Ti}_{33} \mathrm{Zr}_{11} \mathrm{Ni}_{8} \mathrm{Si}_{1}$ metallic glass powders $J$. Alloy Compounds 415 162-9 